\title{
Evaluation of mixed mode (I/II) notch stress intensity factors of sharp V-notches using point substitution displacement technique
}

\author{
Mirzaul Karim Hussain, K.S.R.K. Murthy \\ Department of Mechanical Engineering, Indian Institute of Technology Guwabati, Guwahati-781039, India \\ mirzau@iitg.ac.in, bttps://orcid.org/0000-0003-4300-360X \\ ksrkm@iitg.ac.in, bttps://orcid.org/0000-0002-9112-8557
}

\begin{abstract}
In this paper, determination of the accurate notch stress intensity factors (NSIFs) have been demonstrated using a recently proposed technique: The point substitution displacement technique (PSDT) for the sharp Vnotched configurations. In this technique, certain optimal point(s) on the notch flanks are obtained where the displacements are found to be highly accurate. Using the PSDT, the NSIFs are determined from the finite element (FE) displacements at these optimal point(s). The NSIFs of two pure mode I and two mixed mode (I/II) examples have been determined and excellent agreement of the present results with the published results is observed. The PSDT is efficient, robust and easy to be implemented in the available FE code.
\end{abstract}

KEYwORDS. V-notch; NSIF; Stress intensity; Finite element; Mixed mode

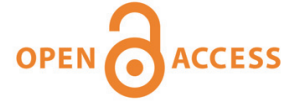

Citation: Hussain, M. K., Murthy, K. S. R. K., Evaluation of mixed mode (I/II) notch stress intensity factors of sharp V-notches using point substitution displacement technique, Frattura ed Integrità Strutturale, 48 (2019) 599-610.

Received: 30.11 .2018

Accepted: 25.02 .2019

Published: 01.04.2019

Copyright: (C) 2019 This is an open access article under the terms of the CC-BY 4.0, which permits unrestricted use, distribution, and reproduction in any medium, provided the original author and source are credited.

\section{INTRODUCTION}

$\mathrm{S}$ harp V-notches are frequently encountered in many engineering applications and structures. Due to the presence of these notches, a very high local stresses and stress gradient is observed close to the notch tip. The presence of notch drastically decreases the load-bearing capacity of the component and may cause damage to structures subjected to both static and variable loads. Therefore, a very accurate assessment of the strength of the singularity is desired near the notch tip. Williams [1] investigated plane V-notched configurations. In linear elastic fracture mechanics (LEFM), notch stress intensity factors (NSIFs) are widely used to characterize the singular stress field in the vicinity of the notch tip. The singularity stress field in the vicinity of the notch tip can be stated in the form of $K r^{1-\lambda} f_{i j}(\theta)$ here $K$ is the notch stress intensity factor, $r$ is the radial distance from the notch tip, $\lambda-1$ is the order of stress singularity and $f_{i j}(\theta)$ are the angular stress components [1]. Due to the widespread use of the NSIFs in brittle [2-7] and fatigue [8,9] fracture criteria, many efforts have been put forward to develop various post-processing techniques [10-29] to calculate NSIFs.

Gross and Mendelson [10] and Carpenter [11] determined NSIFs of sharp V-notches using the boundary collocation method. Chen [12] proposed a body force method to evaluate the NSIFs for problems under tensile and in-plane bending loadings. Noda et al. [13] also used body force method to calculate the NSIFs. Ju and Chung [14] and Liu et al. [15] used 
the least-squares method for determining the NSIFs using the stresses obtained from finite element method (FEM). As these least-squares methods $[14,15]$ use the stress field, they require either very fine meshes at the notch tip or higher order Williams coefficients to attain the accurate NSIFs. Triefi et al. [16] developed a strain energy method to determine the mixed mode NSIFs of sharp V-notches. In another research, Lazzarin et al. [17] proposed a strain energy density technique for the rapid evaluation of NSIFs. Many researchers used fractral-like finite element method [18-20] and extended finite element method [21,22] to calculate the NSIFs. Other researchers employed various path independent integrals [23-26] to estimate the NSIFs of sharp V-notches. Apart from these methods, Ayatollahi and Nejati [27] determined the NSIFs along with the higher order terms of Williams coefficients using an overdeterministic method utilizing FE displacements. Recently, Hussain and Murthy [28, 29] developed a collocation technique and a point substitute displacement technique (PSDT) to obtain the mixed mode (I/II) NSIFs using the FE displacements along the notch flank. In their method [29], certain optimal point(s) of the notch tip element along the notch flanks have been identified by minimizing the error in displacements, and interestingly, the displacements and its slope are found to be more accurate at those points. The PSDT utilizes the displacements on the notch flanks at these optimal point(s) to calculate NSIFs accurately. This method is efficient, simple and straightforward to be implemented in the available FE code and can be employed to find the NSIFs using manual calculations.

It is worth noting here that, unlike the availability of well-known quarter point elements $[30,31]$ in the crack problems, no such popular singular elements are currently available for use in the sharp V-notched configurations. Consequently, any post-processing techniques for the determination of the NSIFs should be capable enough to determine the accurate NSIFs yet using the conventional elements at the notch tip and concurrently it should be simple enough to implement in the existing code. The main thrust of the present work is to demonstrate further the efficacy of the above technique, PSDT proposed by Hussain and Murthy [29] in terms accurate estimation of the NSIFs of the specimens having straight and curved boundaries under mode I and mixed mode (I/II) loading conditions.

\section{THEORETICAL BACKGROUND}

A

short description of the formulations for PSDT is presented in this section. However, for more details, one may refer to Ref. [29]. For a homogeneous elastic 2D problems containing sharp V-notch (in Fig. (1)), the displacement field at any nearby point $P(r, \theta)$ under any arbitrary in-plane loading can be given as [14]

$$
\begin{aligned}
u= & \sum_{n=1}^{\infty} \operatorname{Re}\left[\frac{A_{n}}{2 G} r^{\lambda_{n}^{I}}\left\{\left(\kappa+\lambda_{n}^{I} \cos 2 \alpha+\cos 2 \alpha \lambda_{n}^{I}\right) \cos \lambda_{n}^{I} \theta-\lambda_{n}^{I} \cos \left(\lambda_{n}^{I}-2\right) \theta\right\}\right]+u_{R}^{I} \\
& +\sum_{n=1}^{\infty} \operatorname{Re}\left[\frac{B_{n}}{2 G} r^{\lambda_{n}^{I I}}\left\{\left(-\kappa-\lambda_{n}^{I I} \cos 2 \alpha+\cos 2 \alpha \lambda_{n}^{I I}\right) \sin \lambda_{n}^{I I} \theta+\lambda_{n}^{I I} \sin \left(\lambda_{n}^{I I}-2\right) \theta\right\}\right]+u_{R}^{I I} \\
(n & \left.\neq 2 \text { for } B_{n}\right) \\
v= & \sum_{n=1}^{\infty} \operatorname{Re}\left[\frac{A_{n}}{2 G} r^{\lambda_{n}^{I}}\left\{\left(\kappa-\lambda_{n}^{I} \cos 2 \alpha-\cos 2 \alpha \lambda_{n}^{I}\right) \sin \lambda_{n}^{I} \theta+\lambda_{n}^{I} \sin \left(\lambda_{n}^{I}-2\right) \theta\right\}\right] \\
& +\sum_{n=1}^{\infty} \operatorname{Re}\left[\frac{B_{n}}{2 G} r^{\lambda_{n}^{I I}}\left\{\left(\kappa-\lambda_{n}^{I I} \cos 2 \alpha+\cos 2 \alpha \lambda_{n}^{I I}\right) \cos \lambda_{n}^{I I} \theta+\lambda_{n}^{I I} \cos \left(\lambda_{n}^{I I}-2\right) \theta\right\}\right]+v_{\mathrm{R}}^{I I} \\
(n & \left.\neq 2 \text { for } B_{n}\right)
\end{aligned}
$$

where $A_{n}$ and $B_{n}$ are Williams' coefficients corresponding to $n$-th term for mode I and mode II, respectively, $(r, \theta)$ denotes the polar coordinate components, $\operatorname{Re}()$ denotes real part of the variables, Kolosov constant $\kappa$ is equal to $(3-v) /(1+v)$ for plane stress and $3-4 v$ for plane strain conditions, $\gamma(=180-2 \alpha)$ is the notch angle (Fig. (1)), $G=E / 2(1+v)$ is the shear modulus, $v$ and $E$ are the Poisson's ratio and Young's modulus, respectively. $\lambda_{n}^{I}$ and $\lambda_{n}^{I I}$ are the mode I and mode II eigenvalues, respectively, and can be obtained by solving the following characteristic Eqn. (3). The constants displacements $u_{R}^{I}, u_{R}^{I I}$ and $v_{R}^{I I}$ can be shown in Eqn. (4) [27]. 


$$
\begin{aligned}
& \lambda_{n}^{I} \sin 2 \alpha+\sin 2 \lambda_{n}^{I} \alpha=0 \\
& \lambda_{n}^{I I} \sin 2 \alpha-\sin 2 \lambda_{n}^{I I} \alpha=0 \\
& u_{\mathrm{R}}^{I}=\frac{\kappa+1}{2 G} A_{0} ; \quad u_{\mathrm{R}}^{I I}=-\frac{\kappa+1}{2 G} B_{2} r \sin \theta ; \quad v_{\mathrm{R}}^{I I}=\frac{\kappa+1}{2 G}\left(B_{0}+B_{2} r \cos \theta\right)
\end{aligned}
$$

where $A_{0}$ and $B_{0}$ are Williams' coefficients corresponding to the rigid body translation and $B_{2}$ is Williams' coefficient corresponding to the rigid body rotations.

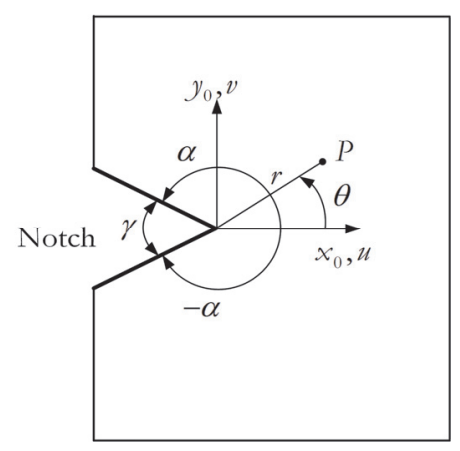

Figure 1: A notch geometry with a local coordinate system.

Mode I and mode II NSIFs can be defined as [10]

$$
\begin{aligned}
& K_{I}=\lim _{r \rightarrow 0}\left(\sqrt{2 \pi} r^{1-\lambda_{1}^{I}} \sigma_{y}\left(\theta=0^{\circ}\right)\right)=\sqrt{2 \pi} \lambda_{1}^{I}\left(1+\lambda_{1}^{I}-\lambda_{1}^{I} \cos 2 \alpha-\cos 2 \alpha \lambda_{1}^{I}\right) A_{1} \\
& K_{I I}=\lim _{r \rightarrow 0}\left(\sqrt{2 \pi} r^{1-\lambda_{1}^{I I}} \tau_{x y}\left(\theta=0^{\circ}\right)\right)=\sqrt{2 \pi} \lambda_{1}^{I I}\left(-1+\lambda_{1}^{I I}-\lambda_{1}^{I I} \cos 2 \alpha+\cos 2 \alpha \lambda_{1}^{I I}\right) B_{1}
\end{aligned}
$$

Considering only the singular terms and constant displacement terms, the displacement field at any nearby point $P(r, \theta)$ under any arbitrary in-plane loading can be given as [14]

$$
\begin{aligned}
u= & \frac{\kappa+1}{2 G} A_{0}+\frac{A_{1}}{2 G} r^{\lambda_{1}^{I}}\left\{\left(\kappa+\lambda_{1}^{I} \cos 2 \alpha+\cos 2 \alpha \lambda_{1}^{I}\right) \cos \lambda_{1}^{I} \theta-\lambda_{1}^{I} \cos \left(\lambda_{1}^{I}-2\right) \theta\right\} \\
& +\frac{B_{1}}{2 G} r^{\lambda_{1}^{I I}}\left\{\left(-\kappa-\lambda_{1}^{I I} \cos 2 \alpha+\cos 2 \alpha \lambda_{1}^{I I}\right) \sin \lambda_{1}^{I I} \theta+\lambda_{1}^{I I} \sin \left(\lambda_{1}^{I I}-2\right) \theta\right\}-\frac{\kappa+1}{2 G} B_{2} r \sin \theta \\
v= & \frac{A_{1}}{2 G} r^{\lambda_{1}^{I}}\left\{\left(\kappa-\lambda_{1}^{I} \cos 2 \alpha-\cos 2 \alpha \lambda_{1}^{I}\right) \sin \lambda_{1}^{I} \theta+\lambda_{n}^{I} \sin \left(\lambda_{1}^{I}-2\right) \theta\right\}+\frac{\kappa+1}{2 G} B_{0} \\
& +\frac{B_{1}}{2 G} r^{\lambda_{1}^{I I}}\left\{\left(\kappa-\lambda_{1}^{I I} \cos 2 \alpha+\cos 2 \alpha \lambda_{1}^{I I}\right) \cos \lambda_{1}^{I I} \theta+\lambda_{1}^{I I} \cos \left(\lambda_{1}^{I I}-2\right) \theta\right\}+\frac{\kappa+1}{2 G} B_{2} r \cos \theta
\end{aligned}
$$

where $A_{1}$ and $B_{1}$ are Williams coefficients for the singular terms for mode I and mode II, respectively. It can be shown that the notch opening displacement (NOD) can be written as [29]

$$
\Delta v=v_{\theta=+\alpha}^{I}-v_{\theta=-\alpha}^{I}=2 v_{\theta=+\alpha}^{I}=2 \frac{A_{1}}{2 G} r^{\lambda_{1}^{I}}\left[\begin{array}{l}
\left(\kappa-\lambda_{1}^{I} \cos 2 \alpha-\cos 2 \alpha \lambda_{1}^{I}\right) \sin \lambda_{1}^{I} \alpha \\
+\lambda_{1}^{I} \sin \left(\lambda_{1}^{I}-2\right) \alpha
\end{array}\right]=2 A_{1} C_{1} r^{\lambda_{1}^{I}}
$$


Similarly, the notch sliding displacement (NSD) can be obtained as [29]

$$
\begin{aligned}
\Delta u=u_{\theta=+\alpha}^{I I}-u_{\theta=-\alpha}^{I I}=2 u_{\theta=+\alpha}^{I I} & =\frac{B_{1}}{G} r^{\lambda_{1}^{I I}}\left[\begin{array}{l}
\left(-\kappa-\lambda_{1}^{I I} \cos 2 \alpha+\cos 2 \alpha \lambda_{1}^{I I}\right) \sin \lambda_{1}^{I I} \alpha \\
+\lambda_{1}^{I I} \sin \left(\lambda_{1}^{I I}-2\right) \alpha
\end{array}\right] \\
& -\frac{\kappa+1}{G} B_{2} r \sin \alpha=B_{1} C_{2} r^{\lambda_{1}^{I I}}+B_{2} C_{3} r
\end{aligned}
$$

where $C_{1}, C_{2}$ and $C_{3}$ are constants which depend upon eigenvalues, $\gamma$ and $\kappa$. Thus, using Eqn. (8) the coefficient $A_{1}$ can be calculated and $B_{1}$ can be calculated from the NSD (Eqn. (9)) under all loading conditions (pure mode I, pure mode II and mixed mode (I/II)). Assuming the isoparametric quadratic quadrilateral elements are deployed at the notch tip, the FE displacement along notch flank nodes 1-2-4 (Fig. (2)) can be written with $r$ being the distance from the notch tip as [29]

$$
v_{\theta=+\alpha}^{F E}=A r^{2}+B r
$$

where the constants $A$ and $B$ are constants and can be obtained from the FE displacements using the following equation

$$
\left\{\begin{array}{c}
A \\
B
\end{array}\right\}=\left[\begin{array}{ll}
r_{2}^{2} & r_{2} \\
r_{4}^{2} & r_{4}
\end{array}\right]^{-1}\left\{\begin{array}{c}
v_{2}^{F E} \\
v_{4}^{F E}
\end{array}\right\}
$$

where $v_{2}^{F E}$ and $v_{4}^{F E}$ are FE displacements at nodes 2 and 4, respectively, and $r_{2}$ and $r_{4}$ are distances of nodes 2 and 4 , respectively, from notch tip 1 . The FE NOD can be expressed as

$$
\Delta v^{F E}=2 A r^{2}+2 B r
$$

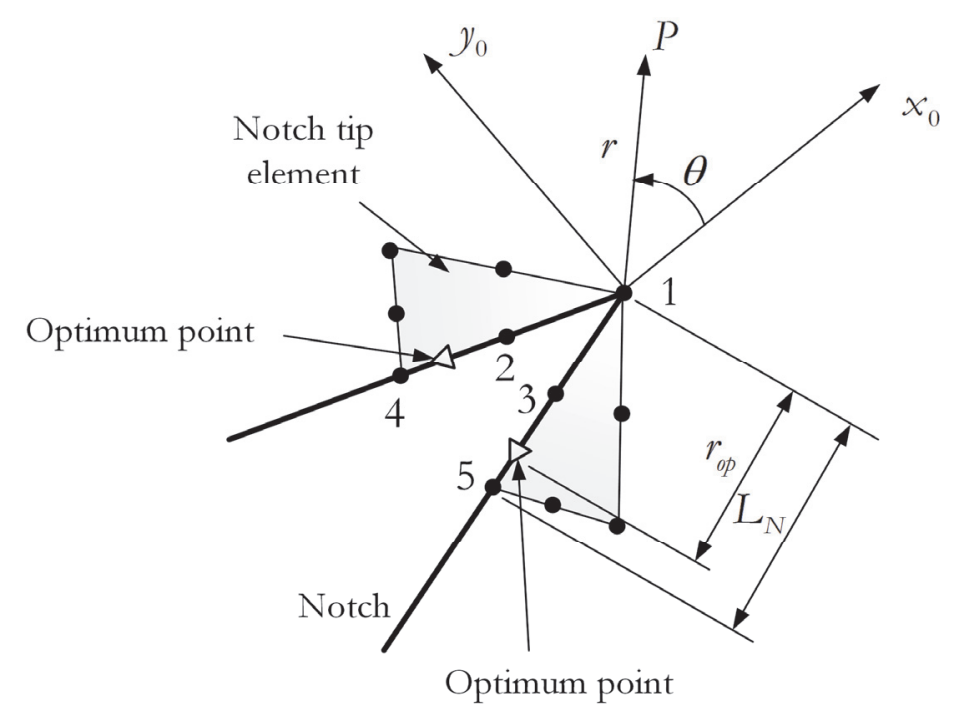

Figure 2: A notch flank finite elements around a notch tip.

The residual $\Re$ between the analytical NOD (Eqn. (8)) and FE NOD (Eqn. (12)) can be written as

$$
\mathfrak{R}=\left(\Delta \nu-\Delta v^{F E}\right)^{2}=\left(2 A_{1} C_{1} r^{\lambda_{1}^{I}}-2 A r^{2}-2 B r\right)^{2}
$$


By minimizing the function $\mathfrak{R}$ with respect to $r$ and after some algebraic manipulations, $r$ and $A_{1}$ can be obtained as [29]

$$
\begin{aligned}
& r=r_{o p}=-\frac{B\left(1-\lambda_{1}^{I}\right)}{A\left(2-\lambda_{1}^{I}\right)} \\
& A_{1}=\frac{A r_{o p}^{2}+B r_{o p}}{C_{1} r_{o p}^{\lambda_{1}^{I}}}=\frac{\left.\Delta v^{F E}\right|_{r=r_{p p}}}{C_{1} r_{o p}^{\lambda_{1}^{I}}}
\end{aligned}
$$

Thus, by using the notch opening displacement $\Delta v^{F E}$ at $r_{o p}, A_{1}$ can be obtained using the Eqn. (15) and hence $K_{I}$ using the Eqn. (5). Taking logarithm on both sides of Eqn. (8), one can write

$$
\ln v=\lambda_{1}^{I} \ln r+\ln A_{1} C_{1}
$$

It can be seen that, Eqn. (16) is a straight line equation whose slope is equal to $\lambda_{1}^{I}$. It can be shown that the slope of the plot of $\ln \left(v_{\theta=+\alpha}^{F E}\right)$ versus $\ln \left(r / L_{N}\right)$ (Eqn. (10)) becomes equal to $\lambda_{1}^{I}$ at the optimal point $r_{o p t}$ (Refer [29] for more details). Here $L_{N}$ is the notch tip element length as shown in Fig. (2).

Similar to the mode I problems, estimation of the $r_{o p}$ or $r_{o p t}$ from $u$-displacement for mode II is not possible as $u_{\theta=+\alpha}^{F E}$ (or $\left.u_{\theta=-\alpha}^{F E}\right)$ contains the term $u_{R}^{I I}$ (Eqn. (9)). Therefore, to calculate the mode II NSIFs, it is presumed that the mode II $u$ displacements are also accurate at the optimal points obtained for the mode I problems using Eq. (14). To calculate both the constants $B_{1}$ and $B_{2}$, two nearby points $r_{o p}=r_{o p t} \times L_{N}$ and $r_{o p}^{\prime}=r_{o p} \pm \Delta r_{o p t} \times L_{N}$ are considered [29]. Therefore, from the FE $u$-displacements at the two close points $r_{o p}$ and $r_{o p}^{\prime}$, the Williams' coefficient $B_{1}$ can be obtained as [29]

$$
B_{1}=\frac{\Delta u_{r_{o p}}^{F E} r_{o p}^{\prime}-\Delta u_{r_{o p}^{\prime}}^{F E} r_{o p}}{C_{2} r_{o p} r_{o p}^{\prime}\left(r_{o p}^{\lambda_{1}^{I I}-1}-r_{o p}^{\prime \lambda_{1}^{I I}-1}\right)}
$$

Again, by substituting FE NSD $\Delta u_{r_{o p}}^{F E}$ and $\Delta u_{r_{o p}^{\prime}}^{F E}$ at $r_{o p}$ and $r_{o p}^{\prime}, B_{1}$ can be obtained using the Eqn. (17) and hence $K_{I I}$ using the Eqn. (5). Finally, the NSIFs can be normalized as $F_{I(I I)}=K_{I(I I)} / \sigma(\tau) \sqrt{\pi}^{\left(1-\lambda_{1}^{I(I I)}\right)}$ and $F_{I(I I)}=K_{I(I I)} R^{\lambda_{1}^{I(I I)}} / F$ for the rectangular and circular plates, respectively.

\section{NUMERICAL EXAMPLES}

7 his section presents a numerical examination of the PSDT for the evaluation of the NSIFs under mode I and mixed mode (I/II) loading conditions. The FE analysis is carried out in ANSYS ${ }^{\circledR}$ [32]. Throughout the domain conventional eight noded quadratic elements are used and no singular elements are utilized at the notch tip. At the notch tip, they are collapsed to form a spider web pattern. Four problems viz. (a) Mode I example of a single edge notched plate under uniform tension (SENT), (b) mode I example of a single edge notched plate under in-plane bending (SENB), (c) mixed mode problem of an angled single edge notched plate under uniform tension (ASENT) and (d) mixed mode problem of a sharp V-notched Brazilian disc (SV-BD) are considered for the demonstration of the efficacy of the PSDT. The notch length to width ratio $a / w=0.5$ is considered for the single edged notch plates and the notch length to radius ratio $a / R=0.5$ is considered for the Brazilian disc. It is assumed that all the specimens are under plane stress condition. Consistent units are employed in all the examples. The thickness of all the specimens is considered as unity. 


\section{Example 1: Mode I Problems}

The first set of examples considered are single edge notched plate under uniform tension (SENT) and single edge notched plate under in-plane bending (SENB) as pure mode I examples (as shown in Fig. (3)). The geometrical parameters considered for the SENT and SENB are as follows: $w=1.0$ and $h=1.2$ as shown in Fig. (3). The uniform tensile loading $\sigma(=1.0)$ and a bending loading $3 \sigma .2 \mathrm{~b} / \mathrm{w}(=7.2)$ are considered for the SENT and SENB specimens, respectively (Fig. (3a) and 3(b)). The notch angles $\gamma=0^{\circ}, 15^{\circ}, 30^{\circ}, 45^{\circ}, 60^{\circ}, 75^{\circ}, 90,105^{\circ}$ and $120^{\circ}$ are considered for validating the present method. Young's modulus $E=1$ and Poisson's ratio $v=0.25$ are considered. One-half (shaded portion in Fig. (3a) and Fig. (3b)) of the geometries is modeled due to the symmetry with appropriate boundary conditions. The typical mesh with 211 number of elements (NE) and 702 number of nodes (NN) used for both the specimens is shown in Fig. (3c). The notch tip element to notch length ratio is considered as $L_{N} / a=0.025$ for both the specimens.

The optimum points $\left(r_{o p t}=r_{o p} / L_{N}\right)$ obtained using Eq. (14) are found to be centered around 0.79 for all the notch angles in the present examples (for a detailed description, one may refer to Ref. [29]). It has been observed that $\Delta v^{F E}$ at the optimal points $r_{o p t}$ obtained using Eqn. (14) are very accurate. The mode I NSIFs calculated at the respective optimal points and are listed in Tab. (1) and Tab. (2) for the SENT and SENB specimens, respectively.

(a)

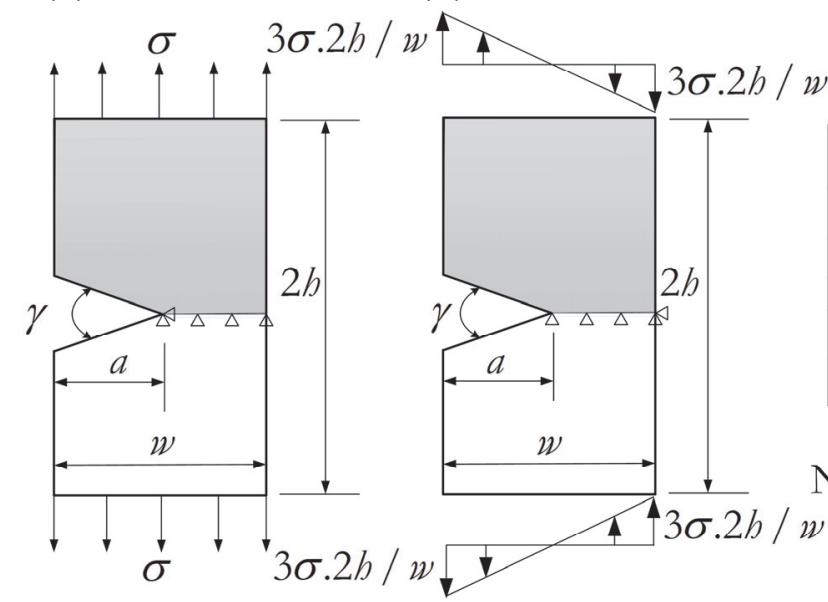

(c)

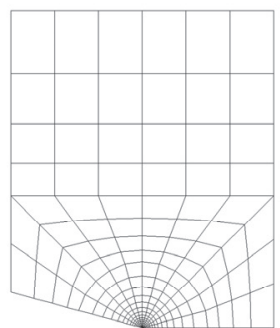

$\mathrm{NE}=211 \mathrm{NN}=702$

$L_{N} / a=0.025$

Figure 3: (a) Single edge notched plate under uniform tension (SENT), (b) single edge notched plate under in-plane bending (SENB) and (c) typical FE mesh used for both SENT and SENB specimens (NE=211, NN=702).

\begin{tabular}{ccccc}
\hline & \multicolumn{5}{c}{$F_{I}$} \\
\cline { 2 - 5 }$\left({ }^{\circ}\right)$ & Present & $\begin{array}{c}\text { Gross and } \\
\text { Mendelson [10] }\end{array}$ & $\begin{array}{c}\text { Zhan and Hahn } \\
{[33]}\end{array}$ & Chen [12] \\
15 & 2.7856 & 2.8237 & 2.8301 & - \\
30 & 2.8019 & - & - & - \\
45 & 2.8279 & 2.8448 & 2.8408 & - \\
60 & 2.8775 & - & - & 2.9440 \\
75 & 2.9620 & 2.9716 & 2.9937 & - \\
90 & 3.1005 & - & - & 3.3220 \\
105 & 3.3191 & 3.3244 & 3.3716 & - \\
120 & 3.6532 & - & 4.0133 & - \\
\hline
\end{tabular}

Table 1: Normalized NSIF $F_{I}$ for the SENT specimen $(a / w=0.5)$. 


\begin{tabular}{ccc}
\hline \multirow{2}{*}{$\gamma\left({ }^{\circ}\right)$} & \multicolumn{2}{c}{$F_{I}$} \\
\cline { 2 - 3 } 0 & Present & Chen [12] \\
15 & 1.4881 & - \\
30 & 1.4922 & - \\
45 & 1.5000 & 1.5010 \\
60 & 1.5185 & - \\
75 & 1.61537 & 1.5530 \\
90 & 1.7164 & - \\
105 & 1.8749 & 1.7140 \\
120 & 2.1185 & - \\
\hline
\end{tabular}

Table 2: Normalized NSIF $F_{I}$ for the SENB specimen $(a / w=0.5)$.

It can be observed that the NSIFs calculated from the present technique are in excellent agreement with the available results (\% relative error is less than 1\% with respect to Chen [12] results). Due to the implementation of the NOD, very accurate values of NSIFs can be attained with coarse meshes.

\section{Example 2: Mixed Mode Example of an Angled Single Edge Notched Plate under Uniform Tension (ASENT)}

The third example considered is a mixed mode example of an angled single edge notched plate under uniform tension (ASENT) to analyze the efficiency of the PSDT under mixed mode loading. The geometry and loading for ASENT are as follows: $w=1.0, b=3.5$ and $\sigma=1.0$ as shown in Fig. (4a). The notch inclination angles $\beta=15^{\circ}, 30^{\circ}$ and $45^{\circ}$ and notch angles $\gamma=0^{\circ}, 30^{\circ}, 60^{\circ}$, and $90^{\circ}$ are considered for determining the mixed mode NSIFs. A Poisson's ratio $v=0.25$ and Young's modulus $E=1$ are considered. A typical FE mesh for the ASENT is shown in Fig. (4b) for $\beta=30^{\circ}$ and $\gamma=30^{\circ}$ with 531 number of elements and 1723 number of nodes. Fig. (4c) shows the enlarged portion near the notch tip with $L_{N} / a=0.025$.

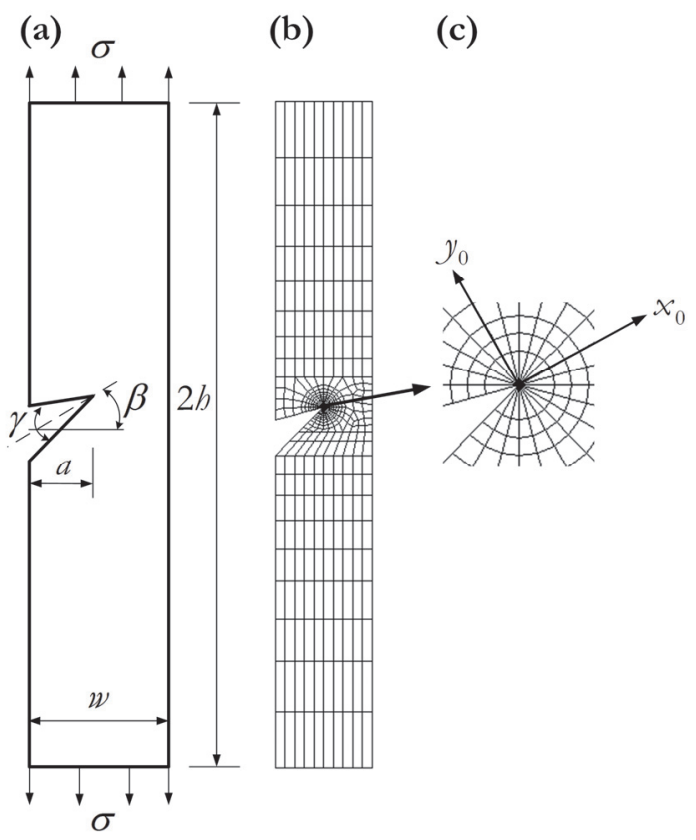

Figure 4: (a) Angled single edge notched plate under uniform tension (ASENT), (b) typical FE mesh used for the ASENT specimen $(\mathrm{NE}=531, \mathrm{NN}=1723)$ and $(\mathrm{c})$ mesh arrangement near the notch tip portion. 
Similar to the pure mode I problem $A_{1}$ can be obtained from $\Delta v^{F E}$ at $r_{o p t}$ using Eqn. (14). $B_{1}$ can be obtained from $\Delta u^{F E}$ at two radii $\left(r_{o p}=r_{o p t} \times L_{N}\right.$ and $\left.r_{o p}^{\prime}=r_{o p}-\Delta r_{o p} \times L_{N}\right)$ using Eqn. (17). $\Delta r_{o p}$ can be considered as 0.002 for calculating the mode II NSIFs [29]. The normalized mixed mode (I/II) NSIFs obtained using the PSDT are listed in Tab. (3). Once again, the results obtained from the present method show a good agreement with the published results for various $\beta$ and $\gamma$. The results in Tab. (3) show that using PSDT by the mere substitution of FE NOD and NSD at the optimal points accurate values of mixed mode (I/II) NSIFs can be obtained.

\begin{tabular}{|c|c|c|c|c|c|}
\hline \multirow{2}{*}{$\beta\left(^{\circ}\right)$} & \multirow{2}{*}{$\gamma\left({ }^{\circ}\right)$} & \multicolumn{2}{|c|}{$F_{I}$} & \multicolumn{2}{|c|}{$F_{I I}$} \\
\hline & & Present & Chen [12] & Present & Chen [12] \\
\hline \multirow{4}{*}{15} & 0 & 2.7108 & - & 0.3970 & - \\
\hline & 30 & 2.7507 & 2.7670 & 0.5468 & 0.5410 \\
\hline & 60 & 2.8790 & 2.8870 & 0.7764 & 0.7660 \\
\hline & 90 & 3.2257 & 3.2300 & 1.1220 & 1.1160 \\
\hline \multirow{4}{*}{30} & 0 & 2.0399 & - & 0.7122 & - \\
\hline & 30 & 2.5315 & 2.5460 & 1.0190 & 1.0100 \\
\hline & 60 & 2.6447 & 2.6530 & 1.4619 & 1.4280 \\
\hline & 90 & 2.9587 & 2.9640 & 2.0576 & 2.0950 \\
\hline \multirow{3}{*}{45} & 0 & 2.1792 & - & 1.0078 & - \\
\hline & 30 & 2.2039 & 2.2170 & 1.3615 & 1.3520 \\
\hline & 60 & 2.2937 & 2.3040 & 1.9383 & 1.9110 \\
\hline
\end{tabular}

Table 3: Normalized NSIFs $F_{I}$ and $F_{I I}$ for the ASENT specimen $(a / w=0.5)$.

Example 3: Mixed Mode Example of a Sharp V-notched Brazilian Disc (SV-BD)

A sharp V-notched Brazilian Disc (SV-BD) as shown in Fig. (5) is considered as the fourth example for analyzing mixed mode (I/II) problem. The radius of the SV-BD is taken as $R=60$ and a compressive loading $F=1.0$ is applied as shown in Fig. (5). The notch length to radius ratio $a / R=0.5$, notch inclination angles $\beta=0^{\circ}, 10^{\circ}, 20^{\circ}$ and $30^{\circ}$ and notch angles $\gamma=30^{\circ}, 60^{\circ}$, and $90^{\circ}$ are considered for determining the mixed mode NSIFs for the SV-BD. A Poisson's ratio $v=0.25$ and Young's modulus $E=1$ are considered. The boundary conditions used for the FE analysis are shown in Fig. (5a). Fig. (5b) shows the typical mesh used for the SV-BD (NE=1833 and NN=5643). Fig. (5c) shows the enlarged portion near the notch tip.

(a)

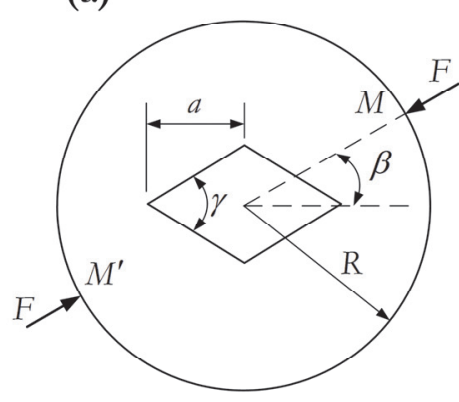

(b)

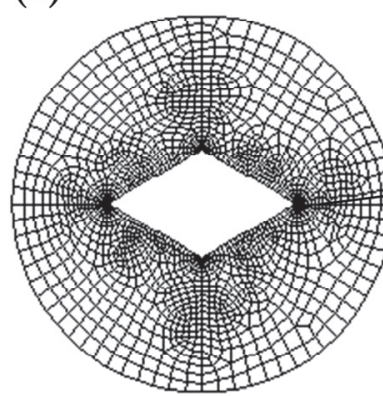

(c)

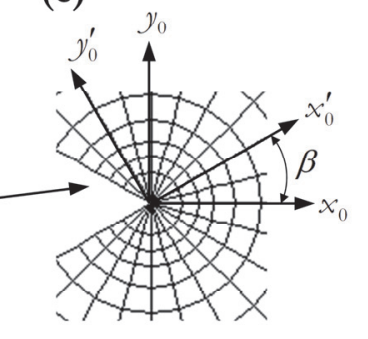

Figure 5: (a) Sharp V-notched Brazilian Disc (SV-BD), (b) typical FE mesh used for the SV-BD specimen (NE=1833, NN=5643) and $(\mathrm{c})$ mesh arrangement near the notch tip portion. 
The mode I and mode II NSIFs are also calculated in a similar way to that of the ASENT specimen. Tab. (4) lists the results of mode I and mode II NSIFs obtained using the PSDT. For comparison, the numerical and experimental results of Ayatollahi and Nejati [34] are also presented in Tab. (4) and it has been noticed that the present results are in good agreement with the published results.

Thus, the results in all the examples indicate that the PSDT is simple and robust. The FE displacements at the optimal points are more accurate than the other points on the notch tip element. The PSDT can provide very good results with coarse mesh even with convention elements at the notch tip.

\begin{tabular}{|c|c|c|c|c|c|c|c|}
\hline \multirow[b]{2}{*}{$\beta\left(^{\circ}\right)$} & \multirow[b]{2}{*}{$\gamma\left({ }^{\circ}\right)$} & \multicolumn{3}{|c|}{$F_{I}$} & \multicolumn{3}{|c|}{$F_{I I}$} \\
\hline & & Present & $\begin{array}{c}\text { Ayatollahi } \\
\text { and Nejati } \\
{[34]} \\
\text { (FEM) }\end{array}$ & $\begin{array}{l}\text { Ayatollahi and } \\
\text { Nejati [34] } \\
\text { (Experimental) }\end{array}$ & Present & $\begin{array}{c}\text { Ayatollahi } \\
\text { and Nejati } \\
{[34]} \\
\text { (FEM) }\end{array}$ & $\begin{array}{l}\text { Ayatollahi and } \\
\text { Nejati [34] } \\
\text { (Experimental) }\end{array}$ \\
\hline \multirow{3}{*}{0} & 30 & 0.7213 & 0.7100 & 0.7400 & 0.0027 & 0.0000 & 0.0200 \\
\hline & 60 & 1.1530 & 1.1300 & 1.1700 & 0.0000 & 0.0000 & 0.0500 \\
\hline & 90 & 2.3108 & 2.2900 & 2.2900 & 0.0000 & 0.0000 & 0.0600 \\
\hline \multirow{3}{*}{10} & 30 & 0.5727 & 0.5600 & 0.6000 & 0.7470 & 0.7200 & 0.7200 \\
\hline & 60 & 0.9599 & 0.9400 & 0.9900 & 1.2619 & 1.1700 & 1.1100 \\
\hline & 90 & 2.0187 & 2.0000 & 1.9500 & 2.1169 & 2.0200 & 2.1300 \\
\hline \multirow{3}{*}{20} & 30 & 0.2148 & 0.2000 & 0.2200 & 1.2006 & 1.1800 & 1.1800 \\
\hline & 60 & 0.4940 & 0.4800 & 0.4800 & 1.9260 & 1.8600 & 1.8900 \\
\hline & 90 & 1.3013 & 1.2900 & 1.2700 & 3.0792 & 3.1200 & 3.0300 \\
\hline \multirow{3}{*}{30} & 30 & 0.1980 & - & - & 1.3447 & - & - \\
\hline & 60 & 0.0555 & -0.0100 & 0.0900 & 2.0788 & 2.0200 & 1.9200 \\
\hline & 90 & 0.4395 & - & - & 3.2716 & - & - \\
\hline
\end{tabular}

Table 4: Comparison of the normalized NSIFs $F_{I}$ and $F_{I I}$ for the SV-BD specimen $(a / w=0.5)$.

\section{CONCLUSIONS}

I $\mathrm{n}$ this paper, the efficacy of an FE based NSIF extraction technique: the point substitution displacement technique (PSDT) has been demonstrated by determining the NSIFs of various configurations under mode I and mixed mode (I/II) loading conditions. The NSIFs are determined from the FE notch flank displacements at the optimum point(s) in the notch tip elements. The efficacy of the present method is examined with two mode I and two mixed mode (I/II) problems. The results obtained using the present method is validated with the available results. The results show that the PSDT is simple, robust and easy to be implemented in the available FE code. Further, accurate values of mode I and II NSIFs can be obtained using coarse meshes.

\section{REFERENCES}

[1] Williams, M.L. (1952). Stress singularities resulting from various boundary conditions in angular corners of plates in extension, J. Appl. Mechs., 19, pp. 526-528.

[2] Dunn, M.L. and Suwito, W. (1997). Fracture initiation at sharp notches: Correlation using critical stress intensities, Int. J. Solids Struct., 34(29), pp. 3873-3883. DOI: 10.1016/S0020-7683(96)00236-3

[3] Seweryn, A. (1994). Brittle fracture criterion for structures with sharp notches, Eng. Fract. Mech., 47, pp. 673-81. DOI: 10.1016/0013-7944(94)90158-9 
[4] Berto, F. and Lazzarin, P. (2014). Recent developments in brittle and quasi-brittle failure assessment of engineering materials by means of local approaches, Mater. Sci. Eng. R. Rep., 75, pp. 1-48. DOI: 10.1016/j.mser.2013.11.001.

[5] Dunn, M.L., Suwito, W., Cunningham, S. and May, C.W. (1997). Fracture initiation at sharp notches under mode I, mode II, and mild mixed mode loading, Int. J. Fract., 84, pp. 67-381. DOI: 10.1023/A:1007346203407.

[6] Ayatollahi, M.R., Torabi, A.R. and Azizi, P. (2011). Experimental and theoretical assessment of brittle fracture in engineering components containing a sharp V-notch, Exp. Mech., 51, pp. 919-932. DOI: 10.1007/s11340-010-9401$z$.

[7] Ayatollahi, M.R. and Torabi, A.R. (2011). Failure assessment of notched polycrystalline graphite under tensile-shear loading, Mater Sci. Eng. A., 528, pp. 5685-5695. DOI: 10.1016/j.msea.2011.04.066.

[8] Lazzarin, P. and Livieri, P. (2001). Notch stress intensity factors and fatigue strength of aluminium and steel welded joints, Int. J. Fatigue, 23, pp. 225-232. DOI: 10.1016/S0142-1123(00)00086-4.

[9] Fischer, C., Fricke, W. and Rizzo, C.M. (2016). Review of the fatigue strength of welded joints based on the notch stress intensity factor and SED approaches, Int. J. Fatigue, 84, pp. 59-66. DOI: 10.1016/j.ijfatigue.2015.11.015.

[10] Gross, B. and Mendelson, A. (1972). Plane elastostatic analysis of V-notched plates, Int. J. Fract. Mech., 8 (3), pp. 267-276. DOI: 10.1007/BF00186126.

[11] Carpenter, W.C. (1984). A collocation procedure for determining fracture mechanics parameters at a corner, Int. J. Fract., 24, pp. 255-266. DOI: 10.1007/BF00020740.

[12] Chen, D.H. (1995). Stress intensity factors for V-notched strip under tension or in-plane bending, Int. J. Fract., 70, pp. 81-97, 1995. DOI: $10.1007 /$ BF00018137.

[13] Noda, N.A., Oda, K. and Inoue, T. (1996). Analysis of newly-defined stress intensity factors for angular corners using singular integral equations of the body force method, Int. J. Fract., 76, pp. 243-261. DOI: 10.1007/BF00048289.

[14] Ju, S.H. and Chung, H.Y. (2007). Accuracy and limit of a least-squares method to calculate 3D notch SIFs, Int. J. Fract., 148 (2), pp. 169-183. DOI: 10.1007/s10704-008-9193-7.

[15] Liu, Y., Wu, Z., Liang, Y. and Liu, X. (2008). Numerical methods for determination of stress intensity factors of singular stress field, Eng. Fract. Mech. 75 (16), pp. 4793-4803. DOI: 10.1016/j.engfracmech.2008.06.007.

[16] Treifi, M. and Oyadiji, S.O. (2013). Strain energy approach to compute stress intensity factors for isotropic homogeneous and bi-material V-notches, Int. J. Solids Struct., 50(14-15), pp. 2196-2212.

DOI: $10.1016 /$ j.ijsolstr.2013.03.011

[17] Lazzarin, P., Berto, F. and Zappalorto, M. (2010). Rapid calculations of notch stress intensity factors based on averaged strain energy density from coarse meshes: Theoretical bases and applications, Int. J. Fatigue., 32(10), pp. 1559-1567. DOI: 10.1016/j.ijfatigue.2010.02.017.

[18] Treifi, M., Oyadiji, S.O. and Tsang, D.K.L. (2009). Computation of the stress intensity factors of sharp notched plates by the fractal-like finite element method, Int. J. Numer. Meth. Engng., 77, pp. 558-580. DOI: 10.1002/nme.2425.

[19] Treifi, M., Oyadiji, S.O. and Tsang, D.K.L. (2008). Computations of modes I and II stress intensity factors of sharp notched plates under in-plane shear and bending loading by the fractal-like finite element method, Int. J. Solids Struct., 45(25-26), pp. 6468-6484. DOI: 10.1016/j.ijsolstr.2008.08.013.

[20] Treifi, M., Oyadiji, S.O. and Tsang, D.K.L. (2009). Computations of the stress intensity factors of double-edge and centre V-notched plates under tension and anti-plane shear by the fractal-like finite element method, Eng. Fract. Mech., 76, pp. 2091-2108. DOI: 10.1016/j.engfracmech.2009.05.018.

[21] Yu, T. and Shi, L. (2012). Determination of sharp V-notch stress intensity factors using the extended finite element method, J. Strain Anal. Eng. Des., 47, pp. 95-103. DOI: 10.1177/0309324711433981.

[22] Yi, G., Yu, T., Quoc, T., Ma, C. and Hirose, S. (2017). SIFs evaluation of sharp V-notched fracture by XFEM and strain energy approach, Theor. Appl. Fract. Mec., 89, pp. 35-44. DOI: 10.1016/j.tafmec.2017.01.005.

[23] Sinclair, G.B., Okajima, M. and Griffin J.H. (1984). Path independent integrals for computing stress intensity factors at sharp notches in elastic plates, Int. J. Numer. Meth. Eng., 20(6), pp. 999-1008. DOI: 10.1002/nme.1620200603.

[24] Labossiere, P.E.W. and Dunn, K.L. (1998). Calculation of stress intensities at sharp notches in anisotropic media, Eng. Fract. Mech., 61(5-6), pp. 635-654. DOI: 10.1016/S0013-7944(98)00039-3.

[25] Chang, J.H. and Kang, L.K. (2002). Evaluation of the stress field around a notch tip using contour integrals, Int. J. Eng. Sci., 40(5), pp. 569-586. DOI: 10.1016/S0020-7225(01)00078-7.

[26] Kim, J.K. and Cho, S.B. (2009). Effect of second non-singular term of mode I near the tip of a V-notched crack, Fatigue Fract. Eng. Mater. Struct., 32(4), pp. 346-356. DOI: 10.1111/j.1460-2695.2009.01336.x.

[27] Ayatollahi, M.R. and Nejati, M. (2011). Determination of NSIFs and coefficients of higher order terms for sharp notches using finite element method, Int. J. Mech. Sci., 53(3), pp. 164-177. DOI: 10.1016/j.ijmecsci.2010.12.005. 
[28] Hussain, M.K. and Murthy, K.S.R.K. (2019). Calculation of mixed mode (I/II) stress intensities at sharp V-notches using finite element notch opening and sliding displacements, Fatigue Fract. Eng. Mater. Struct. pp. 1-18.

DOI: $10.1111 /$ ffe. 12977.

[29] Hussain, M.K. and Murthy, K.S.R.K. (2018). A point substitution displacement technique for estimation of elastic notch stress intensities of sharp V-notched bodies, Theor. Appl. Fract. Mec., 97, pp. 87-97. DOI: $10.1016 /$ j.tafmec.2018.07.010.

[30] Henshel, R.D. and Shaw, K.G. (1976). Crack tip finite elements are unnecessary, Int. J. Numer. Meth. Eng., 9, pp. 495-507. DOI: 10.1002/nme.1620090302.

[31] Barsoum, R.S. (1976). On the use of isoparametric finite elements in linear fracture mechanics, Int. J. Numer. Meth. Eng., 10, pp. 25-27. DOI: 10.1002/nme.1620100103.

[32] ANSYS. Theory reference manual. Release 11. Swanson Analysis Systems, Inc., 2007.

[33] Zhao, Z. and Hahn, H.G. (1992). Determining the SIF of a V-notch from the results of a mixed-mode crack, Eng. Fract. Mech., 43(4), pp. 511-518. DOI: 10.1016/0013-7944(92)90195-K.

[34] Ayatollahi, M.R. and Nejati, M. (2011). Experimental evaluation of stress field around the sharp notches using photoelasticity, Mater. Des., 32, pp. 561-569. DOI: 10.1016/j.matdes.2010.08.024.

\section{NOMENCLATURE}

\begin{tabular}{|c|c|}
\hline$a$ & notch length \\
\hline$A, B$ & parameters related to finite element displacements \\
\hline$A_{0}, B_{0}, B_{2}$ & parameters related to rigid body motion \\
\hline$A_{n}(n=1,2,3, \ldots)$ & Williams coefficients for mode I \\
\hline$B_{n}(n=1,3,4, \ldots)$ & Williams coefficients for mode II \\
\hline E & Young's modulus \\
\hline$F_{I}, F_{I I}$ & modes I and II normalized notch stress intensity factors \\
\hline F & compressive point load on the sharp V-notched Brazilian disc \\
\hline G & shear modulus \\
\hline$b$ & semi-height of the notched plate \\
\hline$L_{N}$ & notch tip element length \\
\hline$K_{I}, K_{I I}$ & modes I and II notch stress intensity factors \\
\hline $\mathrm{R}$ & radius of the sharp V-notched Brazilian disc \\
\hline $\mathfrak{R}$ & residual \\
\hline$(r, \theta)$ & polar coordinate components \\
\hline$r_{o p t}$ & optimum point \\
\hline$r_{o p}$ & optimum radius \\
\hline$u, v$ & notch field displacement \\
\hline$w$ & plate width \\
\hline$\alpha$ & parameter related to notch angle \\
\hline$\beta$ & notch inclination angle \\
\hline$\gamma$ & notch opening angle \\
\hline$\kappa$ & Kolosov constant \\
\hline$\lambda_{1}^{I}, \lambda_{1}^{I I}$ & modes I and II eigenvalues correspond to the singularity term \\
\hline$\lambda_{n}^{I}, \lambda_{n}^{I I}$ & modes I and II eigenvalues correspond to the $n$-th term \\
\hline$v$ & Poisson's ratio \\
\hline$\sigma$ & far field stress \\
\hline$\Delta u, \Delta v$ & notch opening and sliding displacements \\
\hline
\end{tabular}


$\Delta v^{F E}, \Delta u^{F E}$

ASENT

FE

FEM

$\mathrm{NE}$

$\mathrm{NN}$

NOD

NSD

NSIF

PSDT

SENB

SENT

SV-BD finite element notch opening and sliding displacements

angled single edge notched plate under uniform tension

finite element

finite element method

number of elements

number of nodes

notch opening displacement

notch sliding displacement

notch stress intensity factor

point substitution displacement technique

single edge notched plate under in-plane bending

single edge notched plate under uniform tension

sharp V-notched Brazilian disc 